\title{
De-Escalation as a Therapeutic Strategy for Dual Diagnosis Patients in Psychiatry
}

\author{
Ambros A Uchtenhagen* \\ Research Institute for Public Health and Addiction, Zurich University, Switzerland
}

*Corresponding author: Ambros Uchtenhagen, Research Institute for Public Health and Addiction, Konrad Strasse 32 CH-8005 Zurich University, Zurich, Switzerland.

Received Date: February 04, 2020

Published Date: February 11, 2020

Abstract

Schizophrenic patients with a substance abuse condition present one of the highest risks for violent behaviour. The traditional safety measures used in psychiatry are still in force but challenged by a trend to avoid all involuntary action, in respect of patient autonomy. There is an urgent need to develop strategies to cope with this situation, which is especially difficult to cope with in case of first encounters with dual diagnosis patients in psychiatry. The risk for open aggressiveness is difficult to assess and to manage in first encounters, avoiding an escalation and working a deescalation strategy. The strategy described in this paper is based on a distinction of the different types of first encounter and on general rules.

\section{Introduction: What is the Problem?}

Research evidence shows that the risk for violent behaviour in schizophrenic patients is high (high suicide rates and high rate of injury to others after discharge [1,2]. These risks are highest in case of concomitant substance abuse, especially multiple substance abuse, well documented since decades [3], and confirmed recently [4]. The type and extent of risk in first encounters with unknown patients is difficult to assess if no anamnestic data are available. Special attention has been given to methods how to predict violence including «imminent violence» $[5,6]$.

Traditional psychiatry usually recurred to enforced interventions, in the interest to prevent violent behaviours and to protect staff. At present, the trend to refrain from involuntary and enforced interventions, in the light of respecting human rights and especially patient rights, is a challenge to such practices. The search for adequate rules how to cope with such risks is under way, as a part of general therapeutic recommendations [7], or as a research effort to learn from surveys how the encounters work in practice [8].

However, violence in psychiatry is an important topic. A European Research Group is dedicated to the study of it, with 70 member scientists and practitioners and 135 member societies from 17 countries [9]. Annual congresses with attendants from 36 countries are a platform to present and discuss all relevant aspects of the topic [10]. The most frequently used measures to prevent harm from violent behaviour are physical restraint (17\%), seclusion (15\%) administering medications (14\%) [9]. Involuntary admissions to psychiatry are still as high as $20 \%$ of all admissions, in a high-income country with adequate service provision [11].

Confronted with this situation, medicine including psychiatry partly decides to refrain completely from any involuntary interventions in practice (no enforced admissions, no closed wards, no enforced treatment, discharge on demand e.a.). Given the aggressive potential of many dual diagnosis patients, such a policy has the consequence that other organisations and third parties (family, neighbors, concerned citizens, police, social services, courts e.a.) take over to prevent and restrict aggressive behaviour. In the worst case, this is done without professional involvement for diagnosis, prevention and therapy. The respective persons have no patient status, are dealt with as healthy offenders, no therapeutic efforts are made to reduce the safety risks.

The intention of this paper is to describe a procedure how to avoid the potential risk of violent behaviour in first encounters with dual diagnosis patients, using de-escalation approaches. 


\section{Typology of First Encounters with Dual Diagnosis Patients}

The most difficult can be involuntary (enforced) encounters, because the negative feelings from being subject to enforcement, its circumstances, the humiliation and the futility of resistance add to the aggressive potential of the condition. Careful symptom observation and control is needed. No inquisitive questioning; empathic questions should convey genuine interest in what happened and what it means, as an invitation to share the frustrating experience. Explain your thoughts and the options you have, preferably before acting. Try to avoid anything that might lead to an escalation of negative feelings and tension.

The sitution is quite different in case of an opportunistic encounter, when the patient makes no attempt at resistance to enforcement, thereby avoiding the unpleasant aspects. It may be due to realistic insight, or else to a need to save time before taking an opportunity to react, or to a feeling of weakness or inability to come to a decision how to react. Whatever the motivation may be, try to acknowledge the non-resistance, help the person to clarify the reasons for it and then to cooperate in finding out what is best for him /her. At the same time, keep an eye on a hidden aggressive tension.

An encounter on a third-party initiative may be complicated by the nature of and the relation to that party. Many special issues have to be taken up. Has the person a realistic knowledge of the third party's motivation, or are there negative phantasies or even paranoid ideas at work? Are there problems with partner, in the family, at the workplace, with other people that could have contributed to an appeal to psychiatry? Meaning well, protecting the patient against him/herself, or with an intention to get rid of him/her? When is it the right time to discuss a participation of the third party in that clarification process?

Finally, there are encounters on the patient's initiative. Ignorant of his/her motivation and intention, an inadequate procedure may cause a withdrawal or else provoke an escalation. In any case there is a need to decide if the patient may go without intervention or if he/she presents a risk to be prevented and how. The responsibility for this decision and all the consequences is high. Imagine a person is afraid of its own aggressive feelings and seeks help to dominate them, is disappointed or humiliated or infuriated by the psychiatrist's attitude and reaction, turns away in anger and what should be prevented is happening. Or else the psychiatrist underestimates the patient, is preoccupied by something else or wants to avoid the responsibility by taking the initiative for an intervention, unwelcomed by the patient and causing resistance and eventually aggressive behaviour. The risk for either case can best be reduced by following some general rules of procedure.

\section{General Rules for Risk Avoidance}

Empathy: be aware of your own feelings, prejudices, fears, in order not to let them guide you in a premature way. Listen to the patient, your questions should carefully try to clarify what you observe and hear. Explain what you say, your impression, your ideas about what could be done, make proposals and listen to what the patient has to say.

Fear management: do not play the hero, profit from the presence of other persons who could eventually assist you when it comes to violent behaviour. You will feel more secure, your decisions will be less influenced by concerns about your own safety. The patient will anticipate the assistance which in turn will help him to control his/ her behaviour. You may send third parties away to demonstrate trust in the patient's self-control, if your relationship has developed to a stage where such trust is perceived to be realistic.

Mediation: Try to consider and, to the extent possible, to involve in due time all parties that are involved directly or indirectly, in order to know about their positions, attitudes, past experience etc. with the patient. In case of joint meetings, try to start out with empathy and neutrality, before coming to conclusions and plans for further procedure. All parties must have their say but discourage attempts from anyone to dominate.

Be prepared: opportunities to test your behaviour in such encounter situations, to train it with the help from more experienced colleagues, are helpful. A range of psychotherapy methods, such as Motivational interviewing, Early intervention methods, Systemic therapy, Behavioural therapy, Contingency management, Assertive community treatment e.a. work on an understanding of the therapeutic process useful for confrontations in first encounters. A dutch project has developed a method for assessing stages and profiles of encounters with dual diagnosis patients, in order to have a better starting point for interventions [12].

\section{Conclusion}

Preventing harm from aggressive behaviour of patients against staff, other patients and themselves is a major problem in present psychiatry and expected by society. All staff must be prepared to cope with it and to know how to act when confronted with potential violence, especially in case of first encounters with dual diagnosis patients.

\section{Acknowledgement}

None.

\section{Conflict of Interest}

Author declare no conflict of interest.

\section{References}

1. Böker W, Häfner H (1973) Gewalttaten Geistesgestörter. Berlin, Springer.

2. Neumann B, Ross T, Opitz-Welke A (2018) Cross-border psychiatric disorder profile: Schizophrenic criminals between law enforcement and law enforcement psychiatry. Law and psychiatry 36(1): 3-13.

3. Volavka J, Laska E, Baker S, Meisner M, Czobor P, et al. (1997) History of violent behaviour and schizophrenia in different cultures. Analyses based on the WHO study on determinants of outcome of severe mental disorders. Br J Psychiatry 171: 9-14. 
4. Stompe T, Ritter K, Schanda H (2018) Patterns of Substance Abuse in Offenders with Schizophrenia- Illness-Related or Criminal Lifestyle? Front Psychiatry 9: 233.

5. Lidtz CW, Mulvey EP, Gardner W (1993) The accuracy of predictions of violence to others. JAMA 269(8): 1007-1011.

6. Mossman D (1994) Assessing predictions of violence: being accurate about accuracy. J Consult Clin Psychol 62(4): 783-792.

7. Kaiser S, Berger G, Conus Ph (2016) Treatment recommendations for schizophrenia from the Swiss Society for Psychiatry and Psychotherapy.

8. The European Violence in Psychiatry Research Group (EViPRG).
9. Cowman S, Björkdahl A, Clarke E, Gethin G, Maguire J, et al. (2017) A descriptive survey study of violence management and priorities among psychiatric staff in mental health services, across seventeen european countries. BMC Health Services Research 17: 59

10. Callaghan P, Oud N, Nijman H, Palmstierna T (2019) Proceedings of the $11^{\text {th }}$ European congress on violence in clinical psychiatry.

11. (2018) Swiss Health Observatory OBSAN Bulletin. Care provision in Swiss psychiatric clinics. OBSAN, Neuchâtel.

12. Neven A, van Warmel A, van den Brink W (2018) Staging and profiling of patients with dual disorders. Tijdschrift Voor Psychiatrie 60(2): 114119. 